\title{
Erratum
}

\section{The latest is the greatest? Results of a structured lecture about aromatase inhibitor use for breast cancer}

\author{
M.C. Gainford, D. McCready, and M. Clemons
}

Breast Cancer Research and Treatment

DOI 10.007/s10549-005-9031-9

The title page of the original shows an incorrect list of authors, and on the third page Figures 2 and 3 were mixed up. The correct Figures 2 and 3 are shown below.

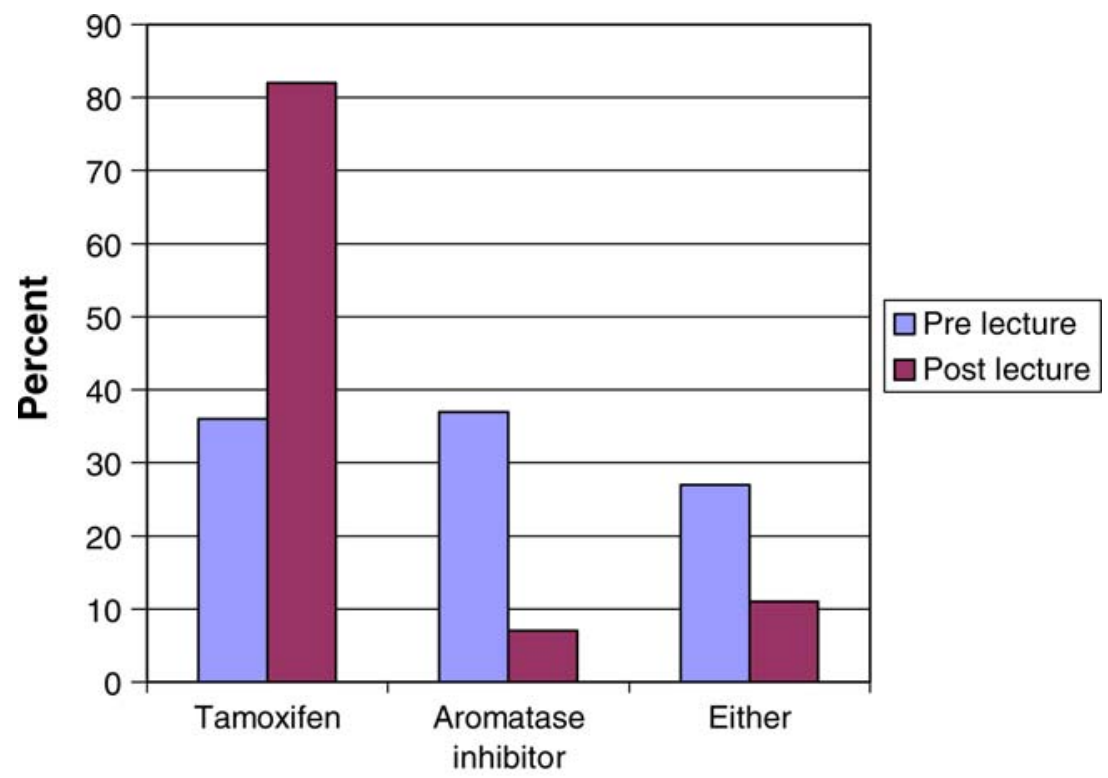

Treatment Choice

Figure 2. What would you consider to be the "best" treatment option for premenopausal women with stage breast cancer?

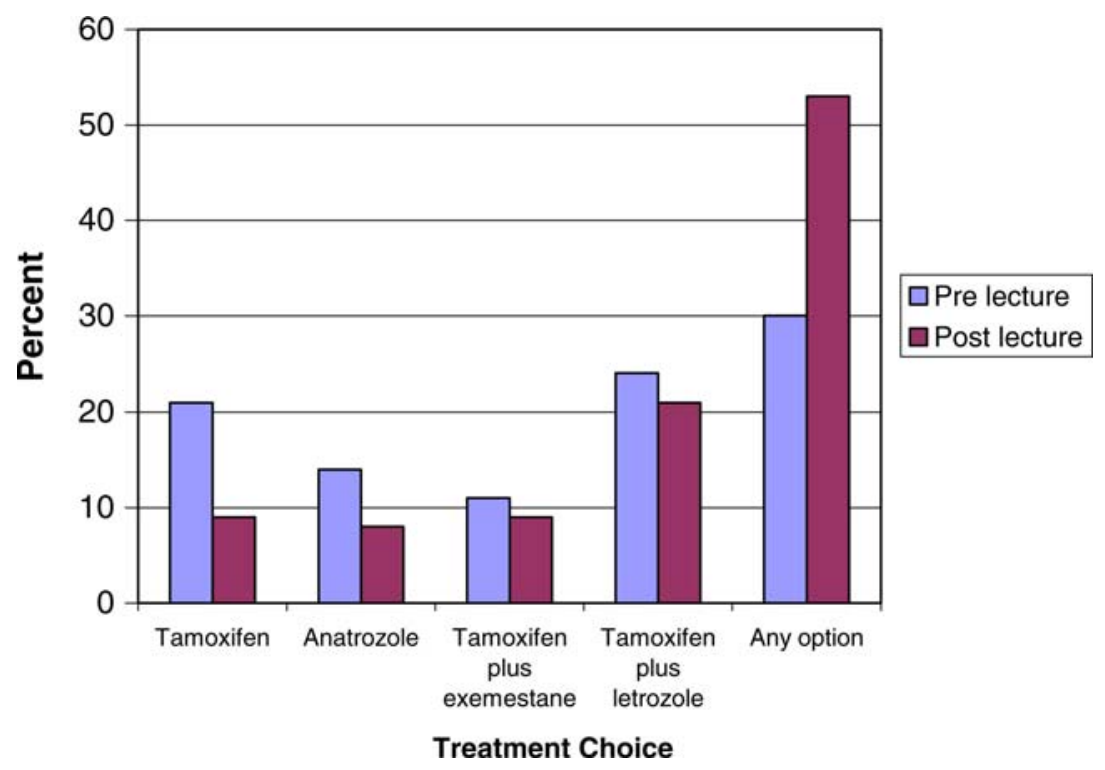

Figure 3. What would you consider to be the "best" treatment option for postmenopausal women with early stage breast cancer? 